Revista de Sociología

№ $19-2005$

Facultad de Ciencias Sociales - Universidad de Chile

(p. 133 - 138)

\title{
LA UNIVERSIDAD PÚBLICA ENTRE SOCIEDADES Y MERCADOS
}

\section{Francisco Delich ${ }^{*}$}

La universidad institución ha cumplido un milenio desde su origen en Bologna. En estas tierras americanas, solo 500 años. Las universidades de Santo D omingo, San Marcos de Lima, o México, rondan esa antigüedad. La Universidad Nacional de Córdoba pronto cumplirá 400.

Las universidades son entonces co-fundadores y productos de Occidente en sus dos vertientes actuales: La europea y la norte-americana.

El salto cuantitativo y cualitativo se produjo hace poco mas de dos siglos, después de las grandes respectivas revoluciones, la Americana y la Francesa.

La universidad latinoamericana de estos tiempos es heredera de la revolución francesa: organizada por y en relación al Estado Moderno y sobre todo, al sujeto privilegiado de aquel proyecto, el ciudadano igual y libre. D e aquel Estado orientado hacia y por la democracia, la educación pública era una condición indispensable. La soberanía del pueblo que proclamaba y a la que aspiraba requería educación para todos.

La educación francesa del Siglo X IX fue el paradigma para América Latina: libertad, igualdad y fraternidad, neutralidad religiosa, predominio de la razón. Jules Ferry fue su ícono.

La revolución americana inventó otro tipo de Estado, el Estado Federal, fundado en el predominio de la libertad como valor supremo, y en consecuencia libertad de los ciudadanos pero también libertad de los mercados, libertad para educar o para no educar.

Los franceses privilegiaron el Estado Nación, centralizado, como responsable de la educación ciudadana. Los americanos consignaron la educación a la iniciativa privada, al interés de los ciudadanos.

América Latina se ha alfabetizado. Independientemente de las disputas acerca del alcance de las estadísticas, de la magnitud del analfabetísimo funcional, es un

${ }^{*}$ Profesor Universidad de Córdoba, Argentina. Ex rector de esa Universidad y de la Universidad de Buenos Aires. 
134 Revista De Sociología

№ 19 - 2005

dato adquirido que la región en su conjunto presenta cifras positivas y razonables de alfabetización.

A partir de los años 50 además, las mujeres se incorporaron masivamente al sistema educativo formal al comienzo en los niveles primarios, luego en los estudios intermedios, y finalmente a comienzos de los años 70 masivamente a las universidades.

La mayor parte de los países de A mérica Latina tuvieron hasta mediados de siglo pasado, un sistema universitario exclusivamente estatal. Las universidades privadas comenzaron su expansión al calor de las limitaciones de las universidades estatales en su oferta educativa y, por otro lado de las demandas, de los mercados.

Las universidades estatales latinoamericanas estuvieron asociadas hasta los años veinte a los regimenes políticos oligárquicos de la región en sus diversas manifestaciones y allí se encuentran la clave de la llamada reforma universitaria de Córdoba, producto de una rebelión estudiantil en Junio de 1918 que logro imponer un conjunto de principios y reivindicaciones organizativos que terminaron por modelar a las universidades de toda la región en el medio siglo subsiguiente.

Como es sabido se propuso entonces, la autonomía de las universidades que implicaba un grado de independencia completa desde el punto de vista académico de los poderes del Estado, que limitaba la ingerencia de los gobiernos en la designación de funcionarios, profesores, aseguraba la libertad de cátedras, el pluralismo en materia de doctrinas e ideologías, la participación estudiantil en el gobierno y la convocatoria a sus graduados a participar de las decisiones de sus cuerpos orgánicos.

La universidad pública se convirtió entonces en una institución sostenida exclusivamente por el Estado, autogestionada y además con el monopolio de la titularización de las distintas profesiones. A diferencia de las universidades estatales europeas y norteamericanas, las universidades públicas de América Latina tuvieron hasta los años sesenta la facultad no solamente de otorgar diplomas de habilitación profesional validos en todo el territorio nacional, sino también habilitar el ejercicio profesional.

Me permito llamar la atención sobre este ultimo punto porque a mi modo de ver constituye el mayor de los atributos de poder reales de las universidades y simultáneamente su mayor debilidad; porque las universidades (en muchos países, publicas y privadas) entregan un diploma que habilita inmediatamente y por si mismas al ejercicio profesional, terminaron conformándose como una institución cuya principal función es la de graduar profesionales que se incluyen inmediatamente en el mercado de trabajo, publico o privado. 
Se genera así una cultura, unas estrategias en el interior de las universidades que establecen como primera prioridad la graduación. Para los estudiantes una meta. Para los profesores una limitación intelectual. Para la institución como tal un acotamiento, a veces salvaje, de su horizonte. Es el momento en el cual la universidad pública es colonizada por intereses privados

El efecto más negativo de la profesionalización de las universidades ha sido sin duda la generación de practicas corporativas y neo-corporativas. Protegidas del Estado por el principio de autonomía, establecidos en muchos países en la propia Constitución Nacional y lejos de cualquier control institucional por parte de la sociedad civil, la institución se recluye en un espacio donde solamente se escuchan las voces de los distintos intereses. El contacto con la sociedad es mínimo, con el Estado casi nulo, indiferente a los mercados.

El autogobierno que sostiene la autogestión, la elección democrática de los representantes de los diversos claustros se convierte muchas veces en un intercambio de favores o eventualmente de homologación de intereses sectoriales. No siempre es así ni en todas las universidades, pero la tendencia al enclaustramiento, a la indiferencia hacia las demandas del Estado, la sociedad y los mercados se convierte en un alejamiento de su propia razón de ser, la construcción de un bien publico.

La universidad publica no obtiene ese carácter por su pertenencia al orden estatal. Estrictamente del Estado solo recibe su presupuesto (y no completamente). En este caso debería denominarse Universidad Estatal sin aditamentos.

Pero cuando mencionamos la Universidad Publica estamos señalando el carácter de una institución capaz de trascender el origen de sus fondos y alcanzar una identificación con el bien común de la sociedad.

Los bienes públicos son construcciones sociales, se definen continuamente en la historicidad y encuentran sus expresiones, constructores, agentes tanto en el Estado como en la sociedad.

La universidad no es en si misma un bien publico sino un camino para la definición y la construcción simbólica y practica de bienes públicos.

La universidad estatal entonces se convierte en universidad publica cuando su acción se orienta hacia los bienes públicos. Uno de los mayores bienes públicos, el bienestar de los ciudadanos, se vincula no solamente ni prioritariamente a la calidad de sus graduados sino a la calidad y amplitud de la investigación científica.

Las universidades publicas se justifican históricamente cuando son capaces de investigar científicamente mas allá del Estado y de los mercados, cuando 
136 Revista De Sociología

№ 19 - 2005

establecen sus prioridades en función de las demandas históricas de los pueblos; cuando son capaces de traspasar las coyunturas y demandas inmediatas estableciendo planes de investigación a mediano y largo plazo, cuando son capaces de traspasar las demandas de los intereses privados inmediatos.

Si las universidades estatales-publicas en el sentido que aquí le asignamos se mantienen como referencias de las sociedades y de los mercados, es justamente por este carácter de independencia de lo inmediato y adhesión al mediano y largo plazo.

Las universidades privadas pueden competir en relación a la calidad de los graduados, Pero por el momento no están en condiciones de competir en la investigación avanzada en las áreas de las ciencias duras que exigen inversiones financieras significativas y que carecen de retorno inmediato en los mercados.

A diferencia de las universidades norteamericanas estrechamente ligadas a los mercados y al aparato de producción privado, que pueden lograr inversiones extraordinarias en la investigación de productos farmacéuticos por ejemplo, porque su transformación en mercancía, en producto es inmediata, las universidades latinoamericanas estatales solo cuentan con recursos limitados y las universidades privadas tienen por su parte muy poco eco entre las empresas.

Por supuesto debe tenerse en cuenta que el componente científico tecnológico en el capitalismo avanzado constituye ahora parte de su naturaleza y en consecuencia la inversión en ciencia y tecnología en las universidades privadas 0 laboratorios extra-universitarios, las convierte inmediatamente en multiplicadores de conocimiento aplicado e impacta normalmente en la calidad del conocimiento transferido en el grado.

Las universidades publicas en A mérica Latina sostienen casi enteramente la investigación en ciencias duras y compiten muy desventajosamente por los grandes centros de investigación extra regionales. Peor aun, sus mejores cuadros de investigadores formados en su seno, son rápidamente cooptados por los grandes centros de investigación del mundo.

No obstante, las universidades publicas constituyen el ultimo espacio de investigación autónoma que probablemente impida estrategias de desarrollo autárquico. La autonomía de la investigación avanzada corre pareja de la capacidad de asociación con centros avanzados internacionales.

La reforma universitaria de 1918 no solamente anuncia el colapso de los regimenes oligárquicos en la educación superior latinoamericana sino también, la incorporación masiva de los sectores medios de la sociedad al control de su orientación y gestión. 
Frang

La universidad estatal gratituita fue un camino para la movilidad social ascendente, allí se formaron las elite políticas que contribuyeron a la democratización de gobiernos y estados en América Latina.

El mayor auge de la expansión de la matricula universitaria, de su prestigio, de su poder, coincidió con la paulatina implementación del modelo de industrialización por sustitución de importaciones que predomino en la región entre 1930 y fines de la década de los 70 y a los cuales me he referido con detalle en mi libro Repensar América Latina (GED ISA, Barcelona, 2004).

La consistencia de aquel modelo asentado sobre la soberanía del Estado Nación que simultáneamente proclamaba el desarrollo económico autárquico a partir de la autosuficiencia productiva y el fortalecimiento de los mercados nacionales con los principios de la universidad reformista, es abrumadora.

Las clases medias emergentes ocuparon posiciones estratégicas en las universidades primero, y en los gobiernos luego. La clase media se auto-producía en las universidades estatales gratuitas y disputaba los gobiernos a partir del monopolio de los títulos profesionales y la legitimidad del conocimiento científico.

Estados acentuaron el control de la economía, con mercados débiles eran consistentes con universidades igualmente monopolicas, escasamente competitivas, solo preocupadas por la formación profesional y por la constitución de elites, de clases dirigentes preparadas para gestionar situaciones monopolticas o oligopolicas tanto en términos políticos como económicos.

La crisis de los llamados estados de bienestar, de los populismos, el acotamiento de la soberanía absoluta de los estados, la irrupción de los mercados en particular de los mercados financieros internacionales, la fragilidad de las fronteras económicas y políticas, el reemplazo de los obreros urbano industriales por los informales en todas las sociedades de la región son cambios de tal magnitud que han condicionado el rol y la legitimidad de las universidades estatales en América Latina.

La multiplicación asombrosa de instituciones privadas universitarias confesionales, corporativas o directamente sectoriales no son sino la manifestación de los límites del espacio universitario estatal las dos ultimas décadas, su confusión, su irrelevancia en algunos casos.

En otros términos el colapso o agotamiento del modelo de industrialización por sustitución de importaciones, la mutación de la sociedad de masas en sociedades fragmentadas, instalada en la agenda de América Latina, invitan a una redefinición de la universidad publica en relación a los Estados y a los mercados, pero sobre todo a su capacidad de redefinir los bienes públicos para servir a los cuales, fue inventada. 